\title{
Immediate effects of Physiotherapy v/s Yoga therapy on Symptoms of Dysmenorrhea
}

\author{
Dr. Urvashi Sharma ${ }^{1}$, Padmaja Gurprasad ${ }^{2}$ \\ ${ }^{1}$ Assistant Professor, Dr DY Patil College of Physiotherapy, Pune, Maharashtra, India
}

2PG Student, Dr DY Patil College of Physiotherapy, Dr DY Patil Vidyapeeth, Pimpri, Pune, Maharashtra, India

\section{ABSTRACT}

\section{Background}

Dysmenorrhea is defined as the cramping pain accompanying menstruation. It is further classified into two types based on pathophysiology write one line about the types Primary dysmennorhea is widely prevalent in the general population. More than $50 \%$ of teenagers and $30-50 \%$ of menstruating women suffer from varying symptoms, such as, uterine cramps, nausea,backache, diarrhoea, giddiness, syncope and fainting. (1). Apart from pharmacological treatment physical exercises have been suggested as non pharmacological treatment. It is seen that exercises have analgesic effect in a non specific way. Various forms of exercise (for.eg. Yoga and physiotherapy) have shown different results in pain relief and premenstrual syndrome. Exercise have been shown as preventive measures as well. $\mathrm{K}$ taping is considered as an adjunct to physiotherapy treatment. (1)

\section{OBJECTIVES:}

1. To assess the effectiveness of yoga poses along with k-taping in primary dysmenorrhea.

2. To assess the effectiveness of physiotherapy exercises along with k-taping in primary dysmenorrhea.

3. To compare the effectiveness of yoga poses v/s physiotherapy exercises along with kinesio taping (KT) in primary dysmenorrhea

\section{MATERIALS AND METHODOLOGY:}

This was a quasi experimental study that included 30 female participants who were suffering from dysmenorrhea. The subjects were randomly divided in to 2 groups; subjects in group A were given physiotherapy exercises and Kinesiotaping and group B were given yoga postures.

These interventions were given on the first and second day of menstruation.

\section{RESULT AND CONCLUSION:}

The study concludes that both yogic postures and physiotherapy exercises helped in immediate reduction of symptoms in primary dysmennorhea. However, none of the treatment was considered superior.

Keywords : Dysmenorrhea, Yoga therapy (YT), physiotherapy (PT), K-taping, immediate effect.

\section{INTRODUCTION}

Dysmenorrhoea is a common monthly gynaecological condition affecting around $50 \%$ of menstruating women. Around $71 \%$ to $75 \%$ women suffer from dysmenorrhea in developing countries. It is associated with menstrual cramps of uterus accompanied with pain and swelling of the area. This may limit around 10\% of women from activity for around 1 to 3 days each menstrual cycle. This may have an overall adverse effect on quality of life and has enlarged the global economic cost. It is found that 
women with dysmenorrhoea are more likely to rest abstaining from activities of daily living leading to absenteeism from the workplace or taking medications to continue the normal daily living activities when compared to women who had normal quality of menstruating periods (1).

Dysmenorrhoea is mainly of two types; primary and secondary dysmenorrhoea. Primary dysmenorrhoea initiates after menarche and is symptomized by cramping menstrual pain in the lower abdomen without any organic pathology. On the other hand, secondary dysmenorrhoea occurs years after menarche and is characterized by pelvic pain, nausea, vomiting, fatigue, back pain, headaches, dizziness, and diarrhoea. Secondary dysmenorrhoea is associated with underlying pathological ailments such as endometriosis, ovarian cysts, pelvic inflammation, myomas or intrauterine devices. $(1,2)$

Factors directly affecting dysmenorrhea are the duration of menstrual flow, younger age at menarche, increased BMI and cigarette smoking. In contrast childbirth appears to relieve dysmenorrhoea. Charu et al (2012) conducted a cross sectional descriptive study on 560 female medical students to evaluate the menstrual characteristics, prevalence and severity of dysmenorrhoea and its effects on the quality of life, particularly absenteeism from college. The severity of menstrual cramps was very high among around 378 women with around 34\% of women experiencing "slightly severe" pain on the pain rating scale. It was found that women whose menarche age was 15 years experienced significantly more severe symptoms when compared to women with 12 to 14 years age as the onset of menarche. Also, dysmenorrhoea was directly proportional to the family history. (2)

In a cross-sectional study conducted on 560 women by Charu et al (2012), it was found that out of 368 women with dysmenorrheoic symptoms, 270 (73.4\%) took allopathic medicines, 213 (57.8\%) took physiotherapy treatment and 147 (39.94\%) took both physiotherapy and allopathic treatment. (1)

Yoga is now an alternative therapy which helps in prevention of many health problems. The word yoga is derived from the sanskrit root yuj meaning to join, bind. Yoga poses now are a common choice to a healthier lifestyle. Yoga's potential mental and physical health benefits are reductions in sympathetic nervous system tone, increases in vagal activity and lowering inflammation; all of which could have favourable endocrine and immune consequences. The physical benefits of yoga are linked to the release of â-endorphins and the shift caused in neurotransmitter levels linked to emotions such as dopamine and serotonin. Very few studies suggested that yoga reduced the severity and duration of pain in primary dysmenorrhea. (3)

None of the previous studies have compared the effectiveness of Physiotherapy and Yoga therapy in treating symptoms of Primary Dysmenorrheoa. The main outcome measures in the previous studies were subjective (Pain). Studies using the objective outcome measures were almost non existent (1, 2, 4-11). Aim of the present study was to compare the effectiveness of both these modalities (Physiotherapy and Yoga Therapy) in the management of Primary Dysmenorrhoea and to find out which modality is superior.

\section{METHODS AND MATERIAL}

Study location: Study was conducted at Dr.D.Y.Patil college of Physiotherapy, Pune.

Sampling method: Convenient sampling was done. 30 females with primary dysmenorrhea were screened and selected. Age group selected was 18-40 years old. 
Females with any history of recent abdominal surgeries, any respiratory or skin conditions were excluded from this study.

\section{Outcome Measures:}

1. Abdominal Swelling

2. Plank Test

1. Abdominal Swelling: Patient stands upright and relaxed. The examiner marks a horizontal line at the highest point of both iliac crests at the level of umbilicus and measures the girth in $\mathrm{cm}$. With the subject standing upright and relaxed, a horizontal measure taken at the height of the iliac crest, usually at the level of the umbilicus. The waist girth is measured in $\mathrm{cm}$. (12)

2. Plank Test: Participants started the test by holding a basic plank position e a prone bridge supported by the forearms and feet. Elbows were vertically below the shoulders with the forearms and fingers extending straight forward. The neck was kept neutral so that the body remained straight from the head to the heels. Participants were required to maintain the prone bridge in a good form throughout the following stages with no rest in between. The score is recorded in seconds. (13)

\section{Procedure and data collection}

30 subjects were randomly divided into group A (KT + Physiotherapy) and group B (Yoga therapy). Baseline outcome measures (Abdominal Swelling, Plank test) were recorded before commencing the treatment.

Group A was given physiotherapy as intervention in which 5 minutes of warm up in the form of neck flexion, extension and rotation, trunk flexion and extension, shoulder rotations, wrist movements, hip movements, ankle movements. Then are asked to perform stretching of neck, biceps, triceps, tensor fasica lata, pelvic muscles, quadriceps, tendo achillies. Each exercise was repeated for 3 times with 10 seconds hold. This step is followed by stretching of specific muscles like stretching the connective tissue around the pelvis, hip flexors and muscles in the inner thigh. After the stretching, now they were asked to perform Kegels exercises for 20 reps with 10 secs hold each. Followed by 5 minutes of relaxation in the form of diaphragmatic breathing. After these exercises KT for menstrual disorders was applied over the lower abdomen. To apply Taping, the starting position of the patient was in standing with spinal flexion. Approximately $15 \mathrm{~cm}$ of KT tape strip was applied over S1with maximum tension with no tension at the ends of the tape. For the ventral application, the patient is instructed to extend the spine. A $10 \mathrm{~cm}$ vertical tape strip was affixed above the symphysis with maximum tension and $15 \mathrm{~cm}$ horizontal strip was affixed over the vertical strip with the maximum tension. Tape ends had no tension. (13) The protocol was followed for 2 days.

Group B performed yoga poses as; supta svatikasana, supta baddhakonasana, adhomukha virasana, adhomukha svastikasana, paschimottanasana. Each pose was held for 5 minutes followed by 5 minutes of shavasana. This treatment was given for Day 1 and Day 2.

After these interventions, Abddominal swelling and Plank test were recorded again immediately after the treatment on day 1 and day 2 .

\section{Data interpretation and Statistical analysis}

For Within group analysis; Paired t test to assess the abdominal swelling and abdominal isometric strength 
pre vs post, day 1 , pre vs post day 2 and pre day 1 vs post day 2

For Between group analysis; Unpaired t test was applied to compare the abdominal swelling and abdominal isometric strength for day 1 and day 2 .

Table 1. represents Mean and Paired t test value at Confidence Interval $\mathrm{p}<0.05$ for Abdominal Swelling after Physiotherapy Treatment on Day 1 and Day 2

\begin{tabular}{|l|l|l|}
\hline $\begin{array}{l}\text { Abdominal } \\
\text { Swelling }\end{array}$ & Day 1 & Day 2 \\
\hline Pre & $88.55 \pm 10.59$ & $88.37 \pm 10.50$ \\
\hline Post & $88.37 \pm 10.55$ & $88.19 \pm 12.60$ \\
\hline t value & 4.44 & 3.32 \\
\hline
\end{tabular}

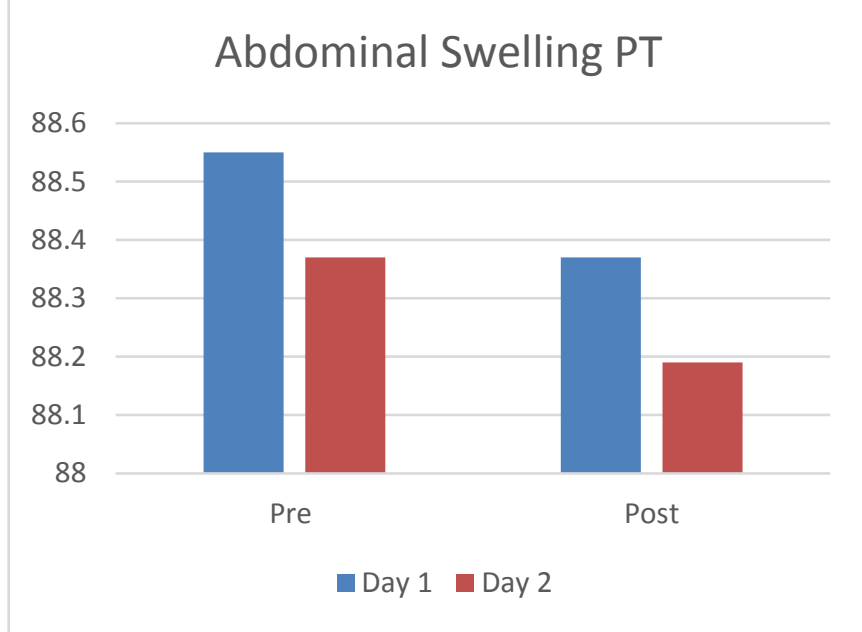

Figure 1. represents Mean and Paired t test value at Confidence Interval $\mathrm{p}<0.05$ for Abdominal Swelling after Physiotherapy Treatment on Day 1 and Day 2

Table 2. represents Mean and Paired t test value at Confidence Interval $\mathrm{p}<0.05$ for Plank test after Physiotherapy Treatment on Day 1 and Day 2

\begin{tabular}{|l|l|l|}
\hline Plank test & Day 1 & Day 2 \\
\hline Pre & $12.2 \pm 2.09$ & $12.96 \pm 2.29$ \\
\hline Post & $12.96 \pm 2.29$ & $13.73 \pm 2.46$ \\
\hline $\mathrm{t}$ value & 3.56 & 4.55 \\
\hline
\end{tabular}

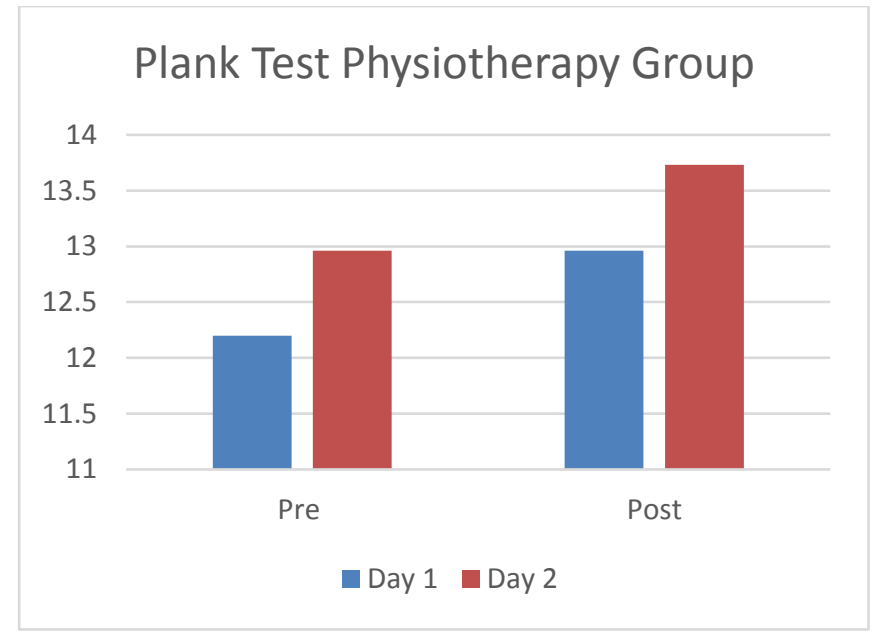

Figure 2. represents Mean and Paired t test value at Confidence Interval $\mathrm{p}<0.05$ for Plank test after Physiotherapy Treatment on Day 1 and Day 2

Table 3. represents Mean and Paired t test value at Confidence Interval $\mathrm{p}<0.05$ for Abdominal Swelling after Yoga Therapy on Day 1 and Day 2

\begin{tabular}{|l|l|l|}
\hline $\begin{array}{l}\text { Abdominal } \\
\text { Swelling }\end{array}$ & Day 1 & Day 2 \\
\hline Pre & $86.62 \pm 9.12$ & $86.40 \pm 9.05$ \\
\hline Post & $86.40 \pm 9.05$ & $86.25 \pm 8.99$ \\
\hline t value & 5.20 & 6.48 \\
\hline
\end{tabular}

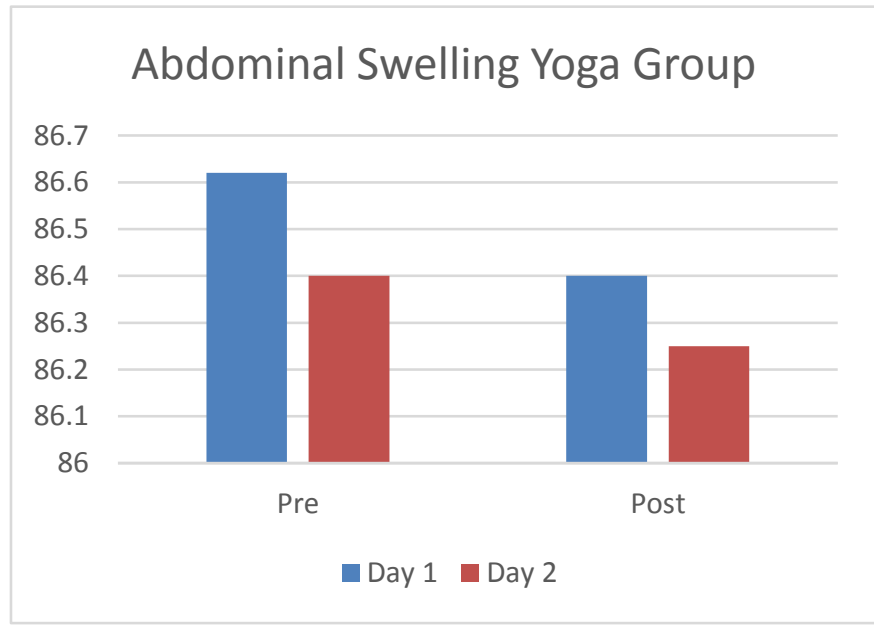

Figure 3. represents Mean and Paired t test value at Confidence Interval $\mathrm{p}<0.05$ for Abdominal Swelling after Yoga Therapy on Day 1 and Day 2 
Table 4. represents Mean and Paired t test value at Confidence Interval $\mathrm{p}<0.05$ for Plank Test after Yoga Therapy on Day 1 and Day 2

\begin{tabular}{|l|l|l|}
\hline Plank test & Day 1 & Day 2 \\
\hline Pre & $13.01 \pm 2.48$ & $13.61 \pm 2.86$ \\
\hline Post & $13.61 \pm 2.86$ & $14.71 \pm 2.76$ \\
\hline $\mathrm{t}$ value & 2.92 & 6.10 \\
\hline
\end{tabular}

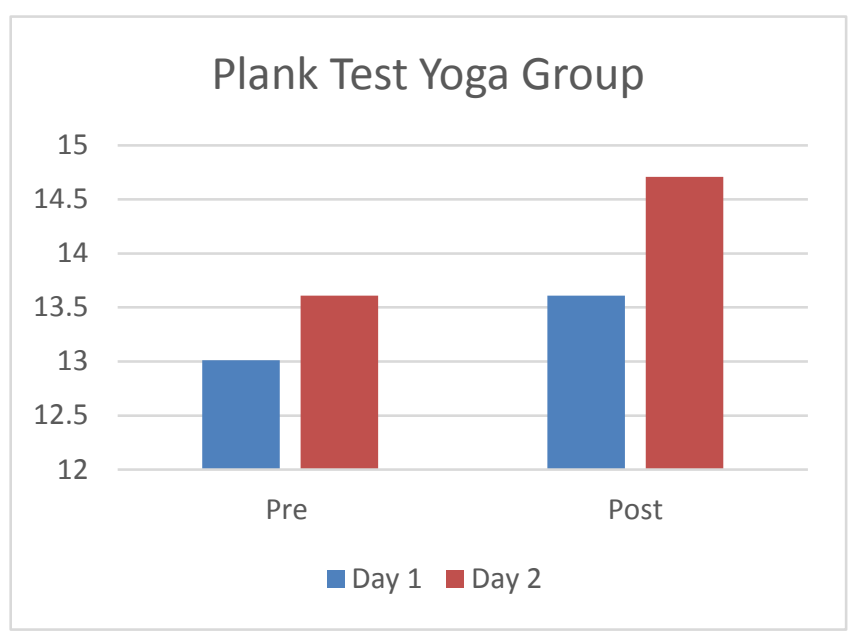

Figure 4. represents Mean and Paired t test value at Confidence Interval $\mathrm{p}<0.05$ for Plank Test after Yoga Therapy on Day 1 and Day 2

Table 5. represents Mean and Paired t test value of Abdominal Swelling for Day 1 Pre and Day 2 Post with Physiotherapy treatment

\begin{tabular}{|l|l|l|}
\hline $\begin{array}{l}\text { Abdominal } \\
\text { Swelling }\end{array}$ & Day 1 Pre & Day 2 Post \\
\hline Mean & 88.55 & 88.19 \\
\hline SD & 10.59 & 10.60 \\
\hline $\mathrm{t}$ value & 4.88 & \\
\hline
\end{tabular}

\section{Abdominal Swelling PT Group}

88.6

88.5

88.4

88.3

88.2

88.1

88

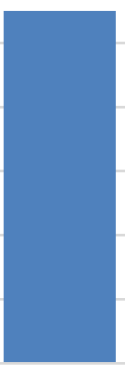

Day 1 Pre

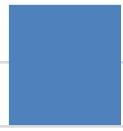

Day 2 Post

Figure 5. represents Mean and Paired t test value of Abdominal Swelling for Day 1 Pre and Day 2 Post with Physiotherapy treatment

Table 6. represents Mean and Paired $t$ test value of Abdominal Swelling for Day 1 Pre and Day 2 Post with Yoga therapy

\begin{tabular}{|l|l|l|}
\hline $\begin{array}{l}\text { Abdominal } \\
\text { Swelling }\end{array}$ & Day 1 Pre & Day 2 Post \\
\hline Mean & 86.62 & 86.25 \\
\hline SD & 9.12 & 8.99 \\
\hline t value & 7.09 & \\
\hline
\end{tabular}

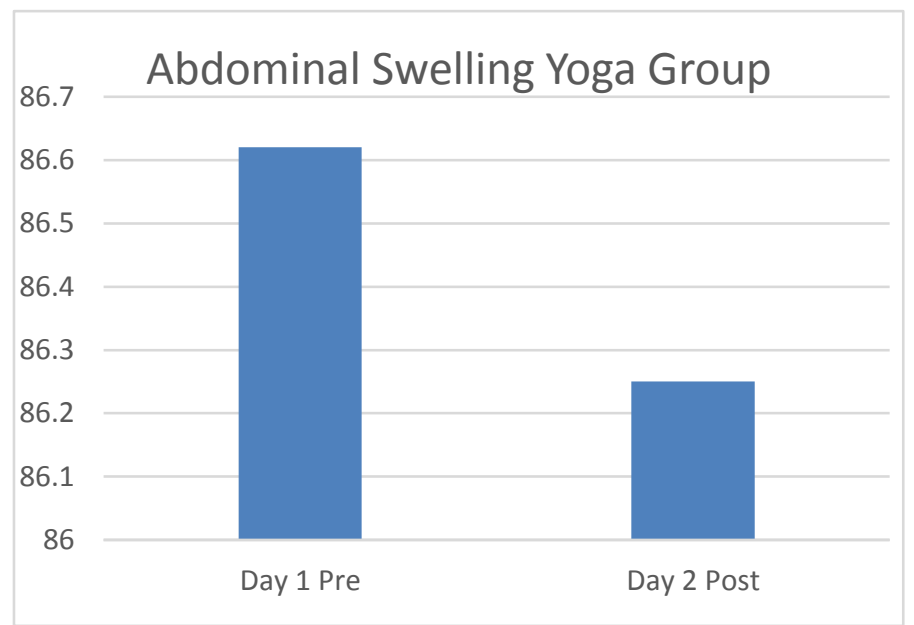

Figure 6. represents Mean and Paired t test value of Abdominal Swelling for Day 1 Pre and Day 2 Post with Yoga therapy 
Table 7. represents Mean and Paired t test value of Plank test for Day 1 Pre and Day 2 Post with Physiotherapy treatment

\begin{tabular}{|l|l|l|}
\hline Plank Test & Day 1 Pre & Day 2 Post \\
\hline Mean & 12.2 & 13.73 \\
\hline SD & 2.09 & 2.46 \\
\hline $\mathrm{t}$ value & 5.51 & \\
\hline
\end{tabular}

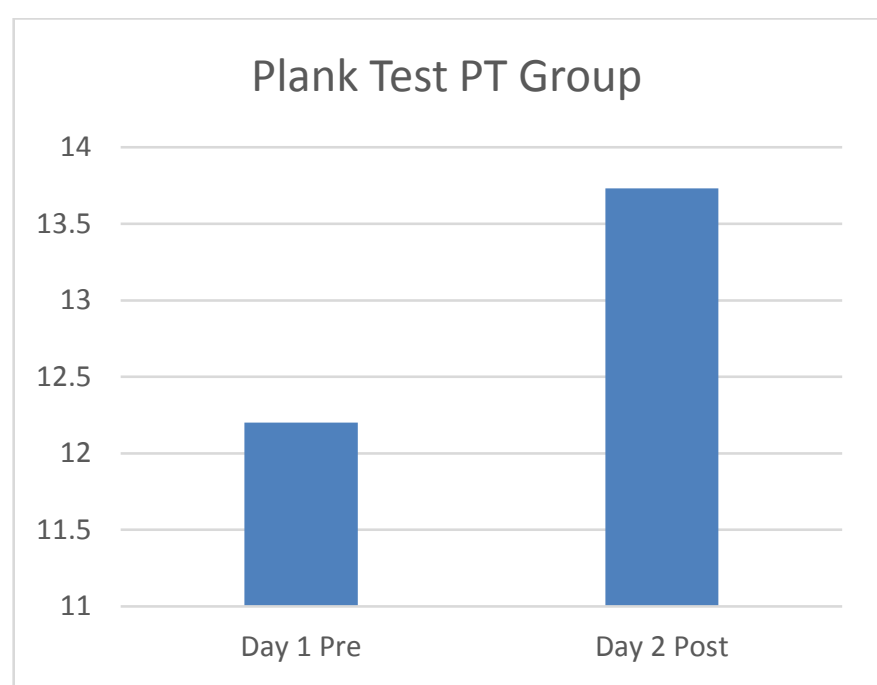

Figure 7. represents Mean and Paired t test value of Plank test for Day 1 Pre and Day 2 Post with Physiotherapy treatment

Table 8. represents Mean and Paired t test value of Plank test for Day 1 Pre and Day 2 Post with Yoga therapy

\begin{tabular}{|l|l|l|}
\hline Plank Test & Day 1 Pre & Day 2 Post \\
\hline Mean & 13.01 & 14.71 \\
\hline SD & 2.41 & 2.76 \\
\hline$t$ value & 8.72 & \\
\hline
\end{tabular}

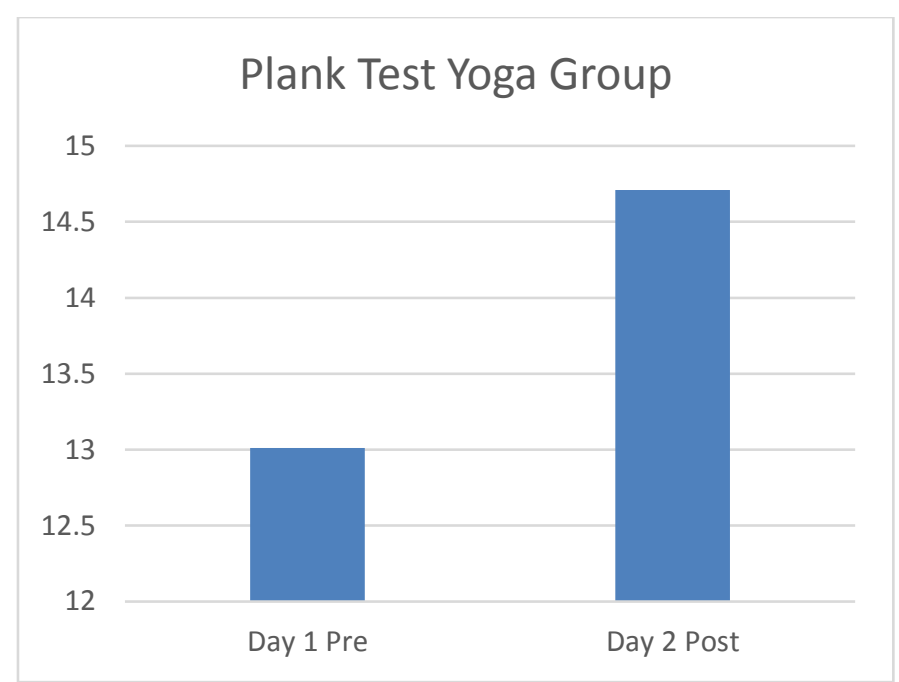

Figure 8. represents Mean and Paired t test value of Plank test for Day 1 Pre and Day 2 Post with Yoga therapy

Table 9. represents Mean, Standard deviations and $\mathrm{t}$ value by assuming unequal variances of Physiotherapy vs Yoga Therapy group for Day 1 for Abdominal Swelling

\begin{tabular}{|l|l|l|}
\hline $\begin{array}{l}\text { Abdominal } \\
\text { Swelling }\end{array}$ & PT & YT \\
\hline Mean & 0.18 & 0.21 \\
\hline SD & 0.14 & 0.14 \\
\hline $\mathrm{t}$ value & 0.54 & \\
\hline
\end{tabular}

\section{Abdominal Swelling for Day 1}

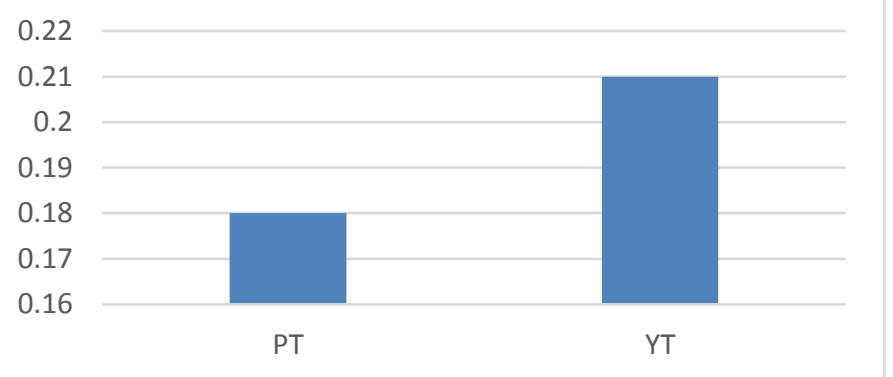

Figure 9. represents Mean, Standard deviations and $\mathrm{t}$ value by assuming unequal variances of Physiotherapy vs Yoga Therapy group for Day 1 for Abdominal Swelling 
Table 10. represents Mean, Standard deviations and $t$ value by assuming unequal variances of Physiotherapy vs Yoga Therapy group for Day 1 for Plank test

\begin{tabular}{|l|l|l|}
\hline Plank test & PT & YT \\
\hline Mean & 0.69 & 0.6 \\
\hline SD & 0.77 & 0.81 \\
\hline $\mathrm{t}$ value & 0.31 & \\
\hline
\end{tabular}

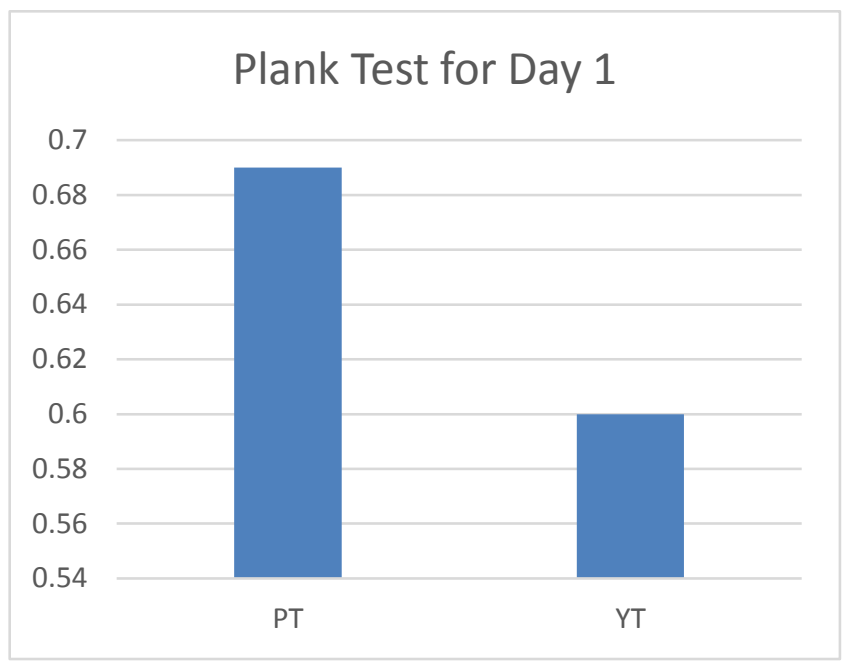

Figure 10. represents Mean, Standard deviations and $t$ value by assuming unequal variances of Physiotherapy vs Yoga Therapy group for Day 1 for Plank test

Table 11. represents Mean, Standard deviations and $\mathrm{t}$ value by assuming unequal variances of Physiotherapy vs Yoga Therapy group for Day 2 for Abdominal Swelling

\begin{tabular}{|l|l|l|}
\hline $\begin{array}{l}\text { Abdominal } \\
\text { Swelling }\end{array}$ & PT & YT \\
\hline Mean & 0.15 & 0.16 \\
\hline SD & 0.2 & 0.1 \\
\hline $\mathrm{t}$ value & 0.19 & \\
\hline
\end{tabular}

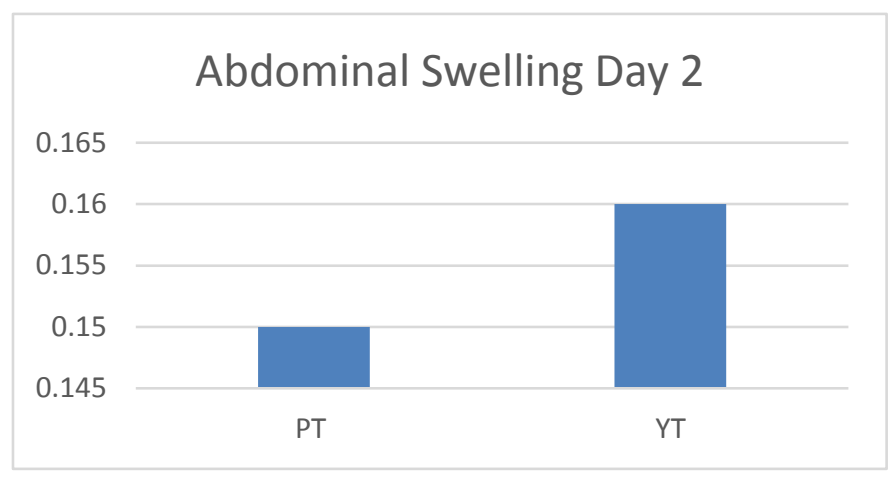

Figure 11. represents Mean, Standard deviations and t value by assuming unequal variances of Physiotherapy vs Yoga Therapy group for Day 2 for Abdominal Swelling

Table 12. represents Mean, Standard deviations and $\mathrm{t}$ value by assuming unequal variances of Physiotherapy vs Yoga Therapy group for Day 2 for Plank test

\begin{tabular}{|l|l|l|}
\hline Plank test & PT & YT \\
\hline Mean & 0.77 & 1.10 \\
\hline SD & 0.63 & 0.72 \\
\hline $\mathrm{t}$ value & 1.34 \\
\hline
\end{tabular}

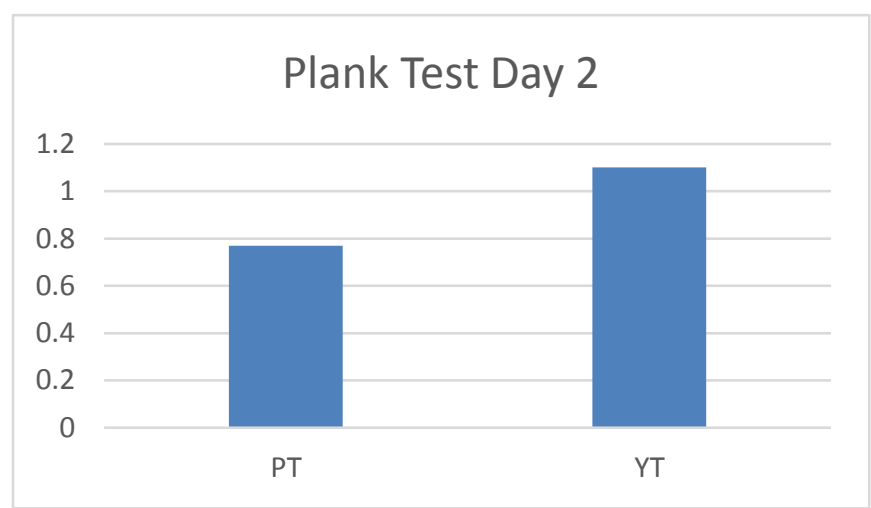

Figure 12. represents Mean, Standard deviations and t value by assuming unequal variances of Physiotherapy vs Yoga Therapy group for Day 2 for Plank test

Table 13. represents Mean, Standard deviations and $\mathrm{t}$ value by assuming unequal variances of 
Physiotherapy Day 1vs Yoga Therapy Day 2 for Abdominal Swelling

\begin{tabular}{|l|l|l|}
\hline $\begin{array}{l}\text { Abdominal } \\
\text { Swelling }\end{array}$ & PT Day 1 & YT Day 2 \\
\hline Mean & 0.18 & 0.16 \\
\hline $\mathrm{SD}$ & 0.14 & 0.1 \\
\hline $\mathrm{t}$ value & 0.33 & \\
\hline
\end{tabular}

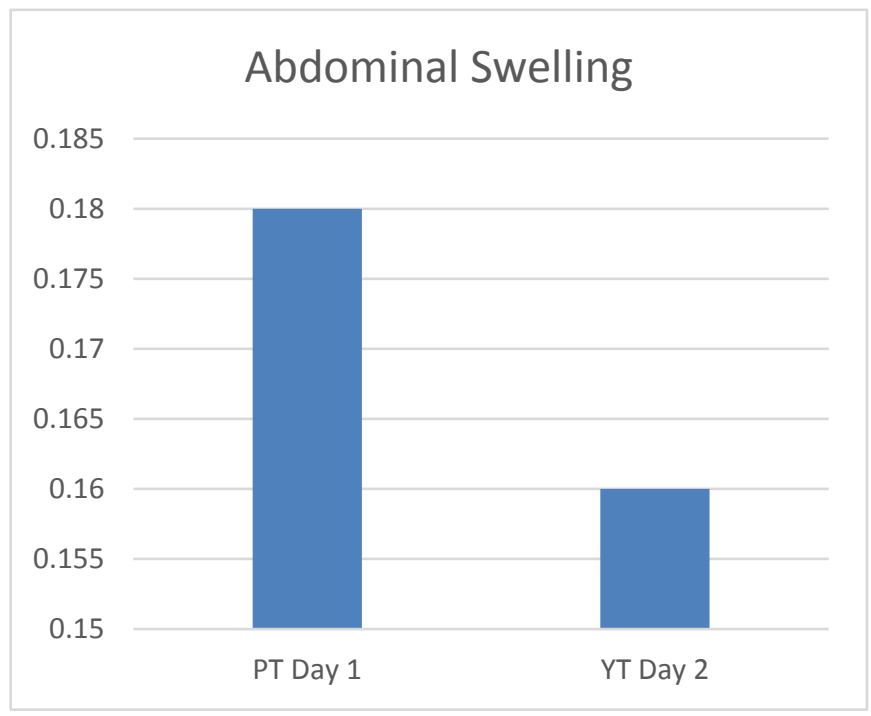

Figure 13. represents Mean, Standard deviations and $t$ value by assuming unequal variances of Physiotherapy Day 1vs Yoga Therapy Day 2 for Abdominal Swelling

Table 14. represents Mean, Standard deviations and $\mathrm{t}$ value by assuming unequal variances of Physiotherapy Day 2vs Yoga Therapy Day 1 for Abdominal Swelling

\begin{tabular}{|l|l|l|}
\hline $\begin{array}{l}\text { Abdominal } \\
\text { Swelling }\end{array}$ & PT Day 2 & YT Day 1 \\
\hline Mean & 0.15 & 0.21 \\
\hline SD & 0.2 & 0.14 \\
\hline $\mathrm{t}$ value & 0.89 & \\
\hline
\end{tabular}

\section{Abdominal Swelling}

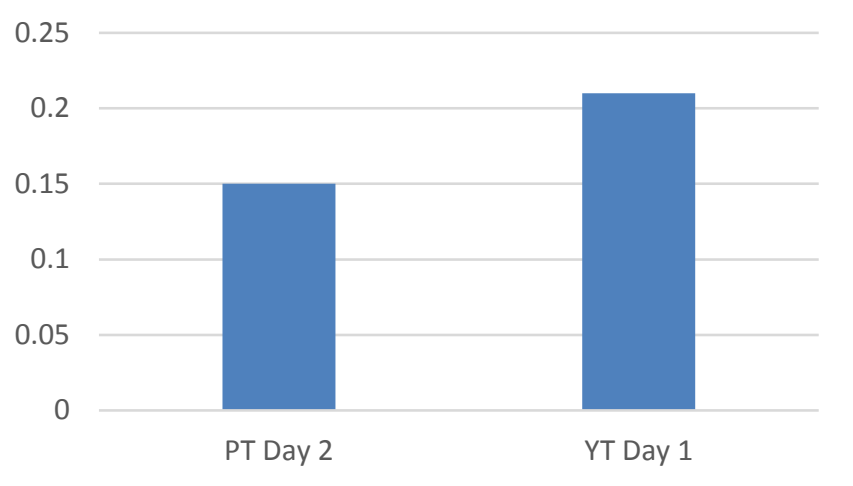

Figure 14. represents Mean, Standard deviations and $t$ value by assuming unequal variances of Physiotherapy Day 2vs Yoga Therapy Day 1 for Abdominal Swelling

Table 15. represents Mean, Standard deviations and $t$ value by assuming unequal variances of Physiotherapy Day 1vs Yoga Therapy Day 2 for Plank test

\begin{tabular}{|l|l|l|}
\hline Plank test & PT Day 1 & YT Day 2 \\
\hline Mean & 0.69 & 1.10 \\
\hline SD & 0.71 & 0.72 \\
\hline$t$ value & 1.50 & \\
\hline
\end{tabular}

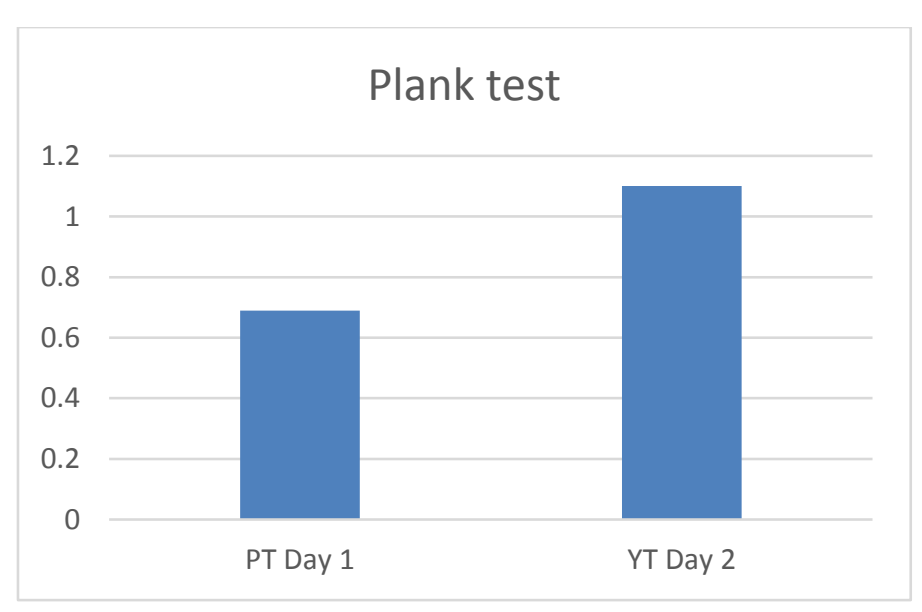

Figure 15. represents Mean, Standard deviations and $t$ value by assuming unequal variances of Physiotherapy Day 1vs Yoga Therapy Day 2 for Plank test 
Table 16. represents Mean, Standard deviations and $t$ value by assuming unequal variances of Physiotherapy Day 2 vs Yoga Therapy Day 1 for Plank test.

\begin{tabular}{|l|l|l|}
\hline Plank test & PT Day 2 & YT Day 1 \\
\hline Mean & 0.77 & 0.6 \\
\hline SD & 0.63 & 0.81 \\
\hline $\mathrm{t}$ value & 0.64 & \\
\hline
\end{tabular}

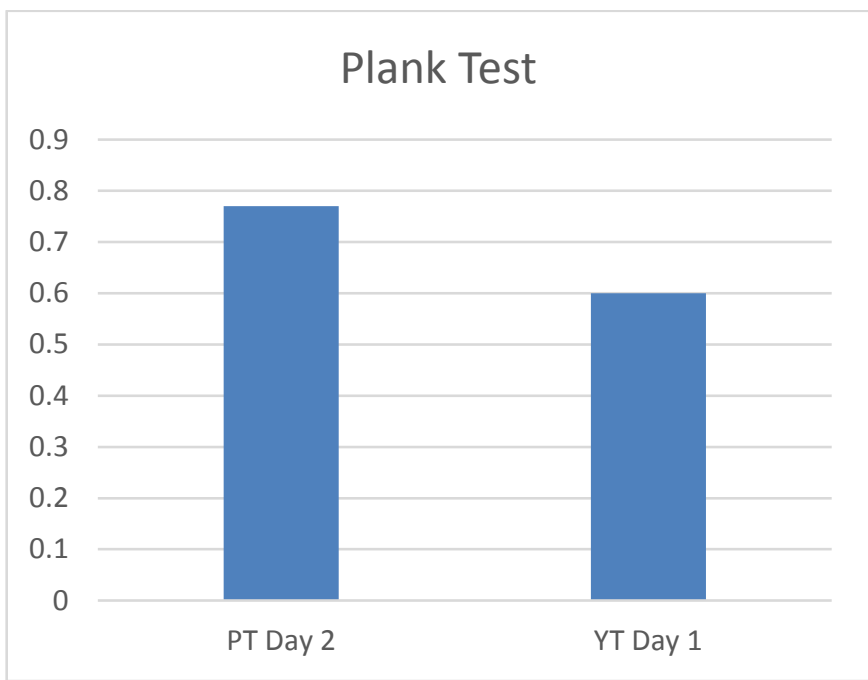

Figure 16. represents Mean, Standard deviations and $t$ value by assuming unequal variances of Physiotherapy Day 2 vs Yoga Therapy Day 1 for Plank test

As for Day 1, the calculated t value (4.44) was greater than the table value of $t$ critical at two tailed (2.16) for abdominal swelling (Table 1) and for plank test $(\mathrm{t}=3.56$ with $\mathrm{p}<0.05)$ for Physiotherapy Group (Table $2)$; the treatment was considered statistically significant. In the same manner, abdominal swelling and plank test improved significantly on day 1 with Yoga therapy $(\mathrm{t}=5.20 ; \mathrm{p}<0.05$ for abdominal swelling and $\mathrm{t}=2.92$; $\mathrm{p}<0.05$ for plank test) (Table 3 and Table 4). On Day 2, abdominal swelling reduced by a mean difference of $0.18 \mathrm{~cm}(\mathrm{t}=3.32 ; \mathrm{p}<0.05)$ (Table 1) and plank test improved by a mean difference of $0.77 \mathrm{~s}$ $(\mathrm{t}=4.55 ; \mathrm{p}<0.05)$ for physiotherapy group (Table 2$)$. In the Yoga therapy group, abdominal swelling reduced by a mean difference of $0.15 \mathrm{~cm}(\mathrm{t}=6.48 ; \mathrm{p}<0.05)$ and plank test improved by a mean difference of $1.1 \mathrm{~s}$ $(\mathrm{t}=6.10 ; \mathrm{p}<0.05)$ on Day 2 (Table 3 and Table 4). When abdominal swelling was assessed on Day 1 before physiotherapy treatment the mean measured $88.55 \mathrm{~cm}$ and after the session, it reduced by $0.36 \mathrm{~cm}$ on Day $2(\mathrm{t}=11.54 ; \mathrm{p}<0.05)$. Plank improved to a mean of 13.3 seconds on Day 2 from 12.2 seconds on Day 1 ( $\mathrm{t}=5.51 ; \mathrm{p}<0.05)$ after Physiotherapy treatment. After 2 days of Yoga therapy abdominal swelling reduced by $0.37 \mathrm{~cm} \quad(\mathrm{t}=7.07 ; \mathrm{p}<0.05$ and Plank improved by 1.7 seconds $(\mathrm{t}=8.72 ; \mathrm{p}<0.05)$. When between group analysis was done, swelling on day 1 had a mean pre post difference of $0.18 \mathrm{~cm}$ in PT group and $0.21 \mathrm{~cm}$ in YT group. This difference was not found to be clinically significant $(t=0.54 ; \mathrm{p}<0.05)$. In the same manner plank test though improved had no significant difference between two groups $(t=0.31$; $\mathrm{p}<0.05$ ) on Day 1 . There were no significant between group differences found on Day 2 for either swelling $(\mathrm{t}=0.19 ; \mathrm{p}<0.05)$ or plank $(\mathrm{t}=1.34 ; \mathrm{p}<0.05)$. None of the differences were found when intergroup analysis was done Day wise for any outcome measure.

\section{DISCUSSION}

It was found from the above findings that although the gross measurements improved significantly within groups after either of the treatment; there were no relevant differences found between Physiotherapy or Yoga therapy treatment for improving symptoms of Dysmenorrhoea. This signifies that either of the therapy is equally beneficial for relieving the Dysmenorrhoea related symptoms.

Our findings agree with the study of Kannan and Claydon (2014) who conducted a systematic review to know the efficacy of physiotherapy treatments on 
relieving menstrual pains in women affected with primary dysmenorrhoea and found that along with acupuncture and acupressure therapy, transcutaneous electrical nerve stimulation, heat and yoga helps in the management of primary dysmenorrhoea (2). In a randomized controlled trial conducted by Azima et al (2015), it was found that isometric exercises significantly improved pain (Visual Analogue Scale) related to Primary dysmenorrhoea after second and third months. However, there were no improvements in anxiety levels that was assessed using Spielberger questionnaire (14). Ortiz et al (2015) in a parallel, prospective, randomized controlled trial studied Mexican women affected with Primary Dysmenorrhoea. 174 women were rando, mized in to physiotherapy and no intervention group. Physiotherapy program consisted of overall stretching, specific stretches, Kegel exercises, jogging, and relaxation exercises. The subjects were assessed for 3 months for VAS. A significant reduction in pain was found by the end of the second and third months in the intervention group (5). Tugay et al (2007) compared the effectiveness of TENS and Interferential therapy for the management of Primary Dysmenorrhoea. Visual analog scale (VAS) intensities of menstrual pain, referred lower limb pain, and low back pain were recorded before treatment, and immediately, 8 hours, and 24 hours after treatment. Both the treatment modalities were found to be equivalently effective (7).

Similar to the earlier studies related to the physiotherapy treatment, Yoga therapy also showed improvements in managing symptoms of Primary dysmenorrhoea. Nag et al (2013) studied 113 students for the effect of Yoga on NPRS and progesterone levels after 3 months of intervention. Although Yoga reduced the pain significantly after the period, Progesterone levels had no significant differences after the treatment (6). Rakshaee (2011) studied 92 women for 3 menstrual cycles for the effectiveness of three yoga poses (Cobra, Cat and Fish poses) on pain and pain duration and found improvent in these symptoms when compared to control group (10). Yang and Kim (2016) assessed 40 girls the effectiveness of yoga therapy on menstrual cramps and menstrual distress using VAS and Menstrual distress questionnaire as the outcome measures. They found that both the baseline measures improved significantly (15).

\section{IV.CONCLUSION}

It was found that Physiotherapy and Yoga Therapy were equivalent in treating symptoms of Primary dysmenorrhoea. Neither of the therapies were found to be superior. Future research studies are required on secondary Dysmenorrhoea and with a large sample size and sampling method.

\section{REFERENCES}

[1]. Charu S, Amita R, Sujoy R, Thomas A G. 'Menstrual characteristics' and 'Prevalence and Effect of Dysmenorrhea' on Quality of Life of medical students. International Journal of Collaborative Research on Internal Medicine \& Public Health Vol. 4 No. 4, 2012

[2]. Kannan P, Claydon L.S,Some physiotherapy treatments may relieve menstrual pain in women with primary dysmenorrhea: a systematic review,(2014)Journal of Physiotherapy 60 (2014) 13-21

[3]. B.K.S Iyengar, Light on Yoga, Harper Collins publishers 2013.

[4]. VG Padubidri, SN Daftary, Shaw's textbook of gynaecology, 16th ed, Hopkin \& Bourne, 2011:36

[5]. Ortiz M.I, Marquez S.K.C ,Quezada L.C.R, Canovas G.M, Diaz A.P.J, Effect of a 
physiotherapy program in women with primary dysmenorrhea ,European Journal of Obstetrics \& Gynecology and Reproductive Biology 194 (2015) 24-29 .

[6]. Nag U, Chakravarthy VK, Burra KC,Effect of yoga on progesterone levels and pain relief in primary dysmenorrhea,(2013) IJRRMS 2013;3(2).

[7]. Tugay.N, Akbayrak. T, Demirtürk.F, Karakaya.I.C, Kocaacar.O,Tugay.U, Karakaya M.G, and Demirtürk.F,Effectiveness of Transcutaneous Electrical Nerve Stimulation and Interferential Current in Primary Dysmenorrhea,PAIN MEDICINE Volume 8:Number $4: 2007$

[8]. Chaegil. L,Yongnam P, Youngsook B, The Effect of the Kinesio Taping and Spiral Taping on Menstrual Pain and Premenstrual Syndrome(2013),J. Phys. Ther. Sci. 25: 761-764, 2013.

[9]. Dr. Geeta .S. Iyengar,The practice of women during the whole month, published by the Iyengar Yoga Association (UK) April 2009

[10]. Guruprasad P, Sharma U, Palekar T. Immediate Effect of Yoga Postures v/s Physiotherapy Exercises Along with K-Taping on Pain in Dysmenorrhea (2019) IJRST 6(2): 487-494

[11]. Rakhshaee Z,Effect of Three Yoga Poses (Cobra, Cat and Fish Poses) in Women with Primary Dysmenorrhea: A Randomized Clinical Trial,(2011) North American Society for Pediatric and Adolescent Gynecology. Published by Elsevier Inc.

[12]. ACSM's Guidelines for Exercise Testing and Prescription. Lippincott Williams and Wilkins. Ninth Edition. 2001: 65

[13]. Tong TK, Wu S, Nie J. Sport-specific endurance plank test for evaluation of global core muscle function. Physical Therapy in Sport. 2014: 5863
[14]. Kumbrink B, K taping an illustrated guide, Springer publication 2012.

[15]. Azima S, Bakhshayesh HR , Abbasnia K, Kaviani M, Sayadi M. Effect of Isometric Exercises on Primary Dysmenorrhea: A Randomized Controlled Clinical Trial. Galen Medical Journal, 2015; 4(1): 26-32

[16]. Yang NY, Kim S D. Effects of a Yoga Program on Menstrual Cramps and Menstrual Distress in Undergraduate Students with Primary Dysmenorrhea: A Single-Blind, Randomized Controlled Trial. The Journal Of Alternative And Complementary Medicine Volume 00, Number 0, 2016, pp. 1-7

\section{Cite this article as :}

Dr. Urvashi Sharma, Padmaja Gurprasad, "Immediate effects of Physiotherapy v/s Yoga therapy on Symptoms of Dysmenorrhea", International Journal of Scientific Research in Science and Technology (IJSRST), Online ISSN : 2395-602X, Print ISSN : 2395-6011, Volume 6 Issue 4, pp. 298-308, JulyAugust 2019. Available at doi : https://doi.org/10.32628/IJSRST196440 Journal URL : http://ijsrst.com/IJSRST196440 